\title{
Innovative Rainmaking Technology by Laser System Initiation Endothermic Reactions in a Way of Natural Lightning Phenomena in the Atmosphere
}

\author{
Shivshankar Kanhuji Chopkar ${ }^{1}$, Dipak Chakrabarty ${ }^{2}$ \\ ${ }^{1}$ Govement Engineering College, Kolhapur University, Kolhapur, Maharashtra, India \\ ${ }^{2}$ Dipak Chakraborty, Physics Research Laboratory, Ahmadabad, Gujarat State, India \\ Email address: \\ Irra.scientistgroup@gmail.com (S. K. Chopkar)
}

\section{To cite this article:}

Shivshankar Kanhuji Chopkar, Dipak Chakrabarty. Innovative Rainmaking Technology by Laser System Initiation Endothermic Reactions in a Way of Natural Lightning Phenomena in the Atmosphere. International Journal of Economy, Energy and Environment.

Vol. 6, No. 3, 2021, pp. 67-70. doi: 10.11648/j.ijeee.20210603.11

Received: September 24, 2020; Accepted: October 21, 2020; Published: June 16, 2021

\begin{abstract}
In the atmosphere, after lightning, precipitation is formed and heavy rainfall occurs. This is a well-known process. This natural lighting phenomenon has been practically demonstrated in the laboratory cloud chamber, A laser beam has to be shot into the cloud region of the atmosphere to create high temperature. This high temperature will break the bonds of atmospheric $\mathrm{N}_{2}$ and $\mathrm{O}_{2}$ and produce $\mathrm{N}$ and $\mathrm{O}$ which will be in excited state $\left(\mathrm{N}^{*}, \mathrm{O}^{*}\right)$. These excited $\mathrm{N}^{*}$ and $\mathrm{O}^{*}$ are very unstable. They immediately fall to the ground state through endothermic reactions. These endothermic reactions absorb heat from the cloud region. As a result, temperature of the cloud region falls, condensation takes place, form rain drops, act as natural seeds are created and it rains. Its use as rain drain by Laser system from ground for Green environment. "Laser photons photo-dissociate atmospheric compounds $\mathrm{N}_{2}$ and $\mathrm{O}_{2}$ and form ozone $\left(\mathrm{O}_{3}\right)$ and nitrogen molecules $(\mathrm{NO})$. Increase of $\mathrm{O}_{3}$ and $\mathrm{NO}$ concentration after lightning has also been experimentally observed. That this lightning phenomenon created through artificial lightning by laser system can produce rain in the atmosphere has been practically proved as "Laser-induced water condensation in air". Scientists have succeeded in obtaining raindrops from an altitude of 45 to $75 \mathrm{~m}$ of the atmosphere by terawatt mobile laser. IRRA Scientist Group propose laser system of specification: $10^{12}$ watt, $800 \mathrm{~nm}, 500 \mathrm{~mJ}, 120 \mathrm{fs}$ and $10 \mathrm{~Hz}$ for this research project. The results could be of immense benefit to human being.
\end{abstract}

Keywords: Laser System, Lightning Phenomena, Precipitation, Natural Seeding, Rainfall

\section{Introduction}

Several attempts have been made by various scientist group to create artificial rain by laser. Number of radar observations has reported that intense precipitation is not even present in the clouds before the first discharge, but develops abruptly in the same region after discharge from which the lightning flashes originate. Carls and Brock [2] heated the atmosphere by a laser pulse up to 1600 to $2800 \mathrm{~K}$ and observed water droplet formation. They predicted that high temperature causes ionization of $\mathrm{N}_{2}$ and $\mathrm{O}_{2}$ and, when this ionized air is subjected to more radiation, avalanche breakdown of air can occur. Braun has observed laser induced condensation and water drops formation by shooting self-channeling of high- peak power femtosecond laser pulses in the air. Yoshihara have shown that the pulsed UVlaser irradiation of ambient air induces formation of water droplets or small ice particles in the laboratory. They also observed that $[\mathrm{O}]$ formed in this process quickly reacts with $\mathrm{O}_{2}$ molecules to form $\mathrm{O}_{3}$ Braun, [1]. We did an experiment in which high temperature was created in a closed chamber by high voltage electric spark. Water drops were seen on the walls of the chamber. A team, called terra-mobile-group (TMG), consisting of scientists from Switzerland, Germany and France, have been trying to create artificial rain by laser. This team has done simulation experiment in laboratory cloud chamber and has observed condensation and water drops formation. Rohwetter et al. [8, 9, 13] have shown that ionized filament, generated by ultra-short wave laser pulses induce water-cloud condensation in the sub-saturated 
atmosphere in the altitude region between 45 and $75 \mathrm{~m}$. They also succeeded in producing tiny water particles in moderately humid air in the altitude region 45 to $75 \mathrm{~m}$ of the atmosphere by terawatt mobile laser. But the droplets were about a hundred times too small to fall as raindrop; instead, they remained suspended in the air. The team feels that it is feasible to get larger droplets if the power of the laser is increased to petawatt $\left(10^{15}\right.$ watts $)$ or exawatt $\left(10^{18}\right.$ watts $)$. It appears from the above that laser has not yet succeeded in producing artificial rain. In this paper, a method is described to create artificial rain by laser.

As per IRRA Scientist Group, in the atmosphere, these laboratory tiny water drops, come together, through acceleration and turbulences process by wind force to form big rain drops, which act as natural seeding to form another sets of rain drops, rain occurs.

\section{Theory and Methodology}

For creation of rain, according to well established meteorology theory (can be found in any text book of meteorology), steps are the following:

First (i) creation of low temperature $\rightarrow$ then (ii) condensation $\rightarrow$ then (iii) seed (CCN) formation $\rightarrow$ then (iv) tiny water drop formation and rain

The present methodology is to send laser pulse to the cloud region of the atmosphere to create high temperature. This high temperature will break the bonds of $\mathrm{O}_{2}$ and $\mathrm{N}_{2}$ as follows:

$$
\begin{aligned}
& \mathrm{N}_{2}: \mathrm{N} \equiv \mathrm{N} \rightarrow \mathrm{N}^{*}+\mathrm{N} \\
& \mathrm{O}_{2}: \mathrm{O}=\mathrm{O} \rightarrow \mathrm{O}^{*}+\mathrm{O}
\end{aligned}
$$

In this process, $\mathrm{N}$ and $\mathrm{O}$ in excited state $\left(\mathrm{N}^{*}, \mathrm{O}^{*}\right)$ will be created. These excited $\mathrm{N}^{*}$ and $\mathrm{O}^{*}$ are very unstable and immediately come to the ground state through following reactions:

$$
\begin{array}{r}
\mathrm{N}^{*}+\mathrm{O}_{2} \rightarrow \mathrm{NO}+\mathrm{O} \Delta \mathrm{H}(43.2 \mathrm{kcal} / \mathrm{mol}) \\
\mathrm{O}^{*}+\mathrm{O}_{2}+\mathrm{M} \rightarrow \mathrm{O}_{3}+\mathrm{M} \Delta \mathrm{H}(67.7 \mathrm{kcal} / \mathrm{mol})
\end{array}
$$

The occurrence of reactions 3 and 4 and formation of $\mathrm{NO}$ and $\mathrm{O}_{3}$ have confirmation from NASA laboratory experiments, Sander, [14]. Formation of $\mathrm{O}_{3}$ and $\mathrm{NO}$, after laser shot, has been observed in laser experiment in atmosphere [12]. The reactions 3 and 4 are endothermic and therefore, they need heat energy (amount $\Delta \mathrm{H}$ mentioned in brackets) which is absorbed from the cloud region. As a result, temperature of the cloud region falls (first step of rain formation is achieved and then other steps follow), condensation takes place, seeds $(\mathrm{CCN})$ will be formed and tiny water drops will be created. These tiny water drops will act as natural seeds to result in rainfall. Ozone and nitric oxide, $\mathrm{O}_{3}$ and $\mathrm{NO}$ (formed in reactions 3 and 4) will undergo various reactions to form $\mathrm{HNO}_{3}, \mathrm{NO}_{3} \cdot\left(\mathrm{H}_{2} \mathrm{O}\right)_{\mathrm{n}}, \mathrm{H} .\left(\mathrm{H}_{2} \mathrm{O}\right)_{\mathrm{n}}$ etc. compounds (where the value of $n$ could be as large as 50) together that bind water molecules which may also act as seed to create water droplets and rainfall. In addition, ions $\mathrm{N}_{2}{ }^{+}$and $\mathrm{O}_{2}{ }^{+}$and electrons formed by cosmic rays, can create complex hydrated heavy positive and negative ions e.g. $\mathrm{HNO}_{3}{ }^{-} \cdot\left(\mathrm{H}_{2} \mathrm{O}\right)_{\mathrm{n}}$ (where the value of $n$ could be as large as 50 ) which can also act as seed to create rain. In short, to create artificial rain by laser, endothermic reactions are to be generated in the cloud region. It has been shown earlier how much heat energy is absorbed by endothermic reactions from atmospheric clouds [3-6]. A laser pulse of energy $500 \mathrm{~mJ}$ can dissociate a column of $\mathrm{N}_{2}$ and $\mathrm{O}_{2}$ containing $\left(\sim 0.5 / 2.25^{-18}\right) \sim$ $10^{17}$ molecules which is much higher than the density in the atmosphere.

Laser can be operated from the ground as well as from an aircraft. In former case, laser pulse has to propagate to a height of $\sim 1 \mathrm{~km}$ (cloud height) from the ground. There will be attenuation of energy in this propagation. Kasparian et al. [10] experimented with terawatt laser from the ground and observed tiny raindrops in an altitude of 45 to $75 \mathrm{~m}$ of the atmosphere. To create large water droplets at higher altitudes, the group feels that laser power has to be peta-watt $\left(10^{15}\right.$ watt $)$ or hexa-watt $\left(10^{18}\right.$ watt). If laser is operated from aircraft then attenuation of energy will be less. In that case, laser power can reach the cloud region without much attenuation. It can also cover a large area and can move to any place. Turbulence created by the aircraft in the atmosphere can also create small water drops which would collide with each other and form big rain drops T. Liu, [15].

\section{Discussion}

When a laser pulse of sufficient energy is shot in the atmosphere, it dissociates $\mathrm{N}_{2}$ and $\mathrm{O}_{2}$ and excited species $\mathrm{N}^{*}$ and $\mathrm{O}^{*}$ are formed:

$$
\begin{aligned}
& \mathrm{N}_{2}+\mathrm{h} v \rightarrow \mathrm{N}^{*}+\mathrm{N} \\
& \mathrm{O}_{2}+\mathrm{h} v \rightarrow \mathrm{O}^{*}+\mathrm{O}
\end{aligned}
$$

These excited species are very unstable and quickly convert into $\mathrm{NO}$ and $\mathrm{O}_{3}$ by endothermic reactions and produce rain. Enhancement of these two species has been observed both in the laboratory as well as in the atmosphere after lightning. However, according to Kasparian group, a laser pulse shot in the atmosphere ionizes $\mathrm{N}_{2}$ and $\mathrm{O}_{2}[8,9]$ :

$$
\begin{gathered}
\mathrm{N}_{2}+\mathrm{h} v \rightarrow \mathrm{N}_{2}^{+}+\mathrm{e}^{-} \\
\mathrm{O}_{2}+\mathrm{h} v \rightarrow \mathrm{O}_{2}^{+}+\mathrm{e}^{-}
\end{gathered}
$$

They have observed lightning phenomenon in the laboratory cloud chamber as "Laser induced condensation and water drops formation in the laboratory cloud chamber by Femtosecond -Terawatt mobile laser system". Kasparian [10] group says that it is the ionized species $\mathrm{N}_{2}^{+}$and $\mathrm{O}_{2}^{+}$ which produce rain. But these two species are of micro size which cannot act as seeding agent. Also $\mathrm{N}_{2}{ }^{+}$and $\mathrm{O}_{2}{ }^{+}$radicals are not observed by Kasparian group in laser filamentation experiment but production of $\mathrm{O}_{3}$ and $\mathrm{NO}$ has been observed by them in laser filamentation experiment. Experiment of 
Kasparian group finds condensation and water drop formation and they say in their ionization theory that $\mathrm{N}_{2}{ }^{+}$and $\mathrm{O}_{2}^{+}$act as seeding agent. They also say "Mechanism of laserinduced condensation involves photo dissociation, in which photons break down atmospheric compounds in the atmosphere. This process produces Ozone and Nitrogen oxides, which lead to the formation of Nitric acid particles that bind water molecules together to create water droplets." But there is no seeding and condensation and water drop formation is not due to seeding. Small water drops formed by laser in the laboratory cloud chamber are due only to endothermic reactions (cooling) and this is obvious. In the atmosphere, due to acceleration and turbulence, these small size water drops coalesce and form big rain drops. These rain drops act as natural seeding process to form another sets of rain drops; this chain process continues with heavy rain fall. Flossmann, M.[7], It has been shown in Appendix that the energy required for dissociation is almost half of that required for ionization. That means energy is first used up for dissociation, then the remaining energy (which may not be sufficient for ionization of $\mathrm{N}_{2}$ and $\mathrm{O}_{2}$ ) is delivered for ionization of $\mathrm{N}_{2}$ and $\mathrm{O}_{2}$. Hence dissociation takes place and not ionization. Kasparian group does not talk about dissociation. It is not only near IR laser system, Yoshihara, et al. [16], have discussed in their paper possibility of creating artificial rain by using UV laser.
Our methodology is to send laser pulse to cloud region to break bonds of $\mathrm{O}_{2}$ and $\mathrm{N}_{2}$ (by reactions 1 and 2), create endothermic reactions and condensation (by reactions 3 and 4) and produce rain in the similar way as in lightning. There is attenuation of energy in operating laser from ground. Kasparian group suggests increase of laser power to pet-watt $\left(10^{15}\right.$ watt $)$ or Hex-watt $\left(10^{18}\right.$ watt $)$ to create large water droplet Mejean G, [11]. We will operate from an aircraft in the same way as spraying chemicals from aircraft. A laser pulse of energy $500 \mathrm{~mJ}$ is capable of dissociating a column of $\mathrm{N}_{2}$ and $\mathrm{O}_{2}$ containing $\left(\sim 0.5 / 2.25^{-18}\right) \sim 10^{17}$ molecules which is much higher than the density in the atmosphere.

\section{Additional Uses}

This method can be used for rain harvesting. When huge clouds are present above a lake or dam, a laser beam can be shot into the cloud region; then with blast of clouds heavy rainfall will occur to fill the lake or dam for future use of water. This method can also be used to reduce pollution of the atmosphere by spraying artificial rain on the polluted city. Another use of this method is to stop excess rainfall. Low intensity laser pulse shot into the cloud region will evaporate the clouds from the excess rainfall area. This method can also be used to drive away the rain cloud from the region where rain is not needed.

\section{Operational Flow Diagram}

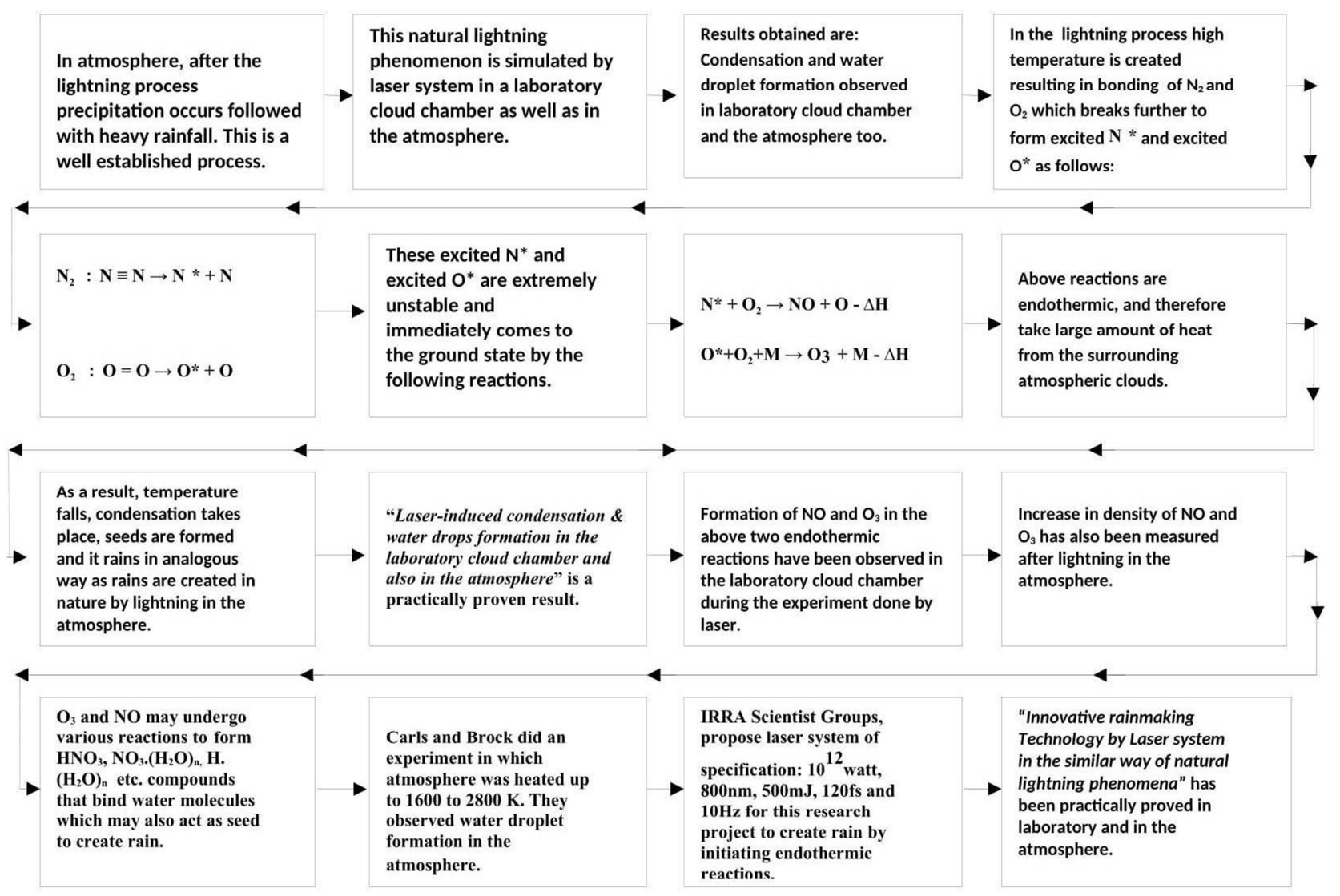

Figure 1. Flow Chart for Rainmaking Technology. 


\section{Conclusion}

Laser can create artificial rain by endothermic reactions in the cloud region of the atmosphere. It may have the following specification: $10^{12}$ watt, $800 \mathrm{~nm}, 500 \mathrm{~mJ}, 120 \mathrm{fs}$ and $10 \mathrm{~Hz}$ for operation from aircraft. If it is operated from ground, power has to be increased at least 100 times. It can be used to (i) fill lake or dam for storing rain water for future use (rain harvesting), (ii) reduce pollution by spraying artificial rain on the polluted city, and (iii) stop rain in the region where it is not needed or where rainfall is in abundance. This method is economical (one time investment), eco-friendly and can be used at any place and at any time.

\section{Acknowledgements}

We express our sincere thanks to several scientists of P. R. L., Ahmadabad for valuable suggestions. We also thank Prof. B. Padmanabha Murthy of J. N. University, New Delhi; Prof. B Korgaokar of University of Pune, Pune; Dr. GL Agrawal of National Environmental Engineering Research Institute, Nagpur; and Dr. A. K. Nath of IIT, Kharagpur, Rajesh Lyengar, P. N. College, Nanded, for help at different stages of this work.

\section{References}

[1] Braun, A., Korn, G., Liu, X., Du, D., Squier, J., and Mourou, G., (1995). "Self-channeling of high- peak power femtosecond laser pulses in air." Opt. Lett., Vol. 20, pp. 73-75.

[2] Carls, J. C. and Brock, J. R., (1987). "Explosion of a water droplet by pulsed laser heating." Aerosol Sci. Technol., Vol. 7, pp. 79-90.

[3] Chopkar, S. K., (1993), "Effect of endothermic reactions associated with lightning on atmospheric chemistry" Indian J. Radio Space Phys. Vol. 22, 128-131.

[4] Chopkar, S. K., (1993), American Meteorological Society in Meteorological \& Geo-astrophysical Abstracts, 44, October (1993) No. 10 (44.10-555) 1993b.
[5] Chopkar, S. K. and Chakrabarty, D. K., (2008). "Artificial rainmaking system in a way of natural phenomena." Indian J. Sci. Technol., Vol. 1, pp. 1-5. Available: http://www.indjst.org.

[6] Chopkar, S. K., D. K. Chakrabarty, and Coauthors, (2010), "Artificial Rainmaking by Laser system", International J. of Meteorology, 35 (355), 363-370, 2010.

[7] Flossmann, M. Manton, A. Abshaev, R. Bruintjes, M. Murakami, T. Prabhakaran and Z. Yao (2018), Peer Review Report on Global Precipitation Enhancement Activities, World Meteorological Organization, pp: 7-12 CH-1211 Geneva 2, Switzerland, 2018. Google Scholar.

[8] Kasparian, J., R. Sauerbrey and S. L. Chin, (2000), The critical laser intensity of self-guided light filaments in air, Appl. Phys. B 71, 877-879.

[9] Kasparian, J. and Coauthors, (2003), White-light filaments for atmospheric analysis, Science, 301, 61-64.

[10] Kasparian, J, P. Rohwetter, L. Wöste, (2012), Laser-assisted water condensation in the atmosphere: a step towards modulating precipitation, Journal of Physics D: Applied Physics, 45 (29).

[11] Mejean G., Ackermann R., Kasparian J., (2006), Improved laser triggering and guiding of megavolt discharges with dual fs-ns pulses, App. Phys. Letts., 88, 021101-3.

[12] Petit, Y., S. Henin, J. Kasparian, (2010), Production of ozone and nitrogen oxides by laser filamentation, Appl. Phys. Lett. 97,021108 .

[13] Rohwetter, P., J. Kasparian, K., (2010), Laser-induced water condensation in air, doi: 10.1038/nphoton.2010.115.

[14] Sander, S. P., R. R. Friedl, (2003), Chemical kinetics and photo-chemical data for use in atmospheric studies, NASA JPL publication, pp. 02-25.

[15] T. Liu, T. Zhang, D. Wang, Z. Huang, (2017) Compact beam transport system for free-electron lasers driven by a laser plasma accelerator. Phys. Rev. Accel. Beams, Feb 1; 20 (2): 110, Google Scholar.

[16] Yoshihara, K., Y. Takatori, K. Miyazaki and Y. Kajit, (2007), Ultraviolet light-induced water- droplet formation from wet ambient air, Proc. Jpn. Acad. Sci. B 83, 320. 